\title{
Restructuring Science, Technology and Mathematics Education for Skills Development and Acquisition in Nigeria
}

\author{
Dr. Mani Ahmed \\ Department of Education Umaru Musa Yar'adua University, Katsina
}

\begin{abstract}
Being a paper presented at the International Conference Organized by West and Solomon Corporative Ideals Limited in Association with National Association for Research Development (NARD) at Onyema Ugochukwu Hall, Akwa Ibom State University, Oyo.
\end{abstract}

Keywords: Restructuring, Science, Technology, Mathematics, Research and Development (R\&D) and Innovation.

\section{Introduction}

The decision to introduce University Basic Education (UBE) was necessitated by the desire of the political leadership to improve the existing system and entrench viable participatory democracy and enhance national socio-economic development as a consequence of a free and compulsory regime of Basic Education. The UBE was also intended as evidence of Nigeria's commitment to the world declarations for "education for all", at Jomtien (1990) and Dakar (2000), as well as the "New Delhi declaration" (1991). There was a follow-up with the conference in Beijing (2001). Other conventions required the nations to double up efforts towards providing more access to education among G9 countries (nine countries with the largest number of illiterate adults) and the OAU decade of education. Pursuant to the above, system expanded due to higher enrolment.

The above scenario gives a picture of gaps in the implementation process of Universal Basic Education program. It suggests that there are many things wrong that need the attention of policy makers, administrators and education managers, if the system is to produce desired results. The needs analysis, restructuring or reorganization constitutes the process of organizing measurable data with a view to assessing the implementation process (input - process - output) of the educational system. It is in the context of this paper, the activities to be carried out to measure the performance of education sector in relation to the implementation of UBE visa-vis the desired outcomes. The concepts "restructuring", "needs analysis", "assessment" and "evaluation" are used interchangeably.

Restructuring requires a systematic exploration of the way things are and the way they should be. It involves identifying materials, problems, opportunities, strengths and evaluating possible solutions that take those issues/challenges into consideration. Restructuring is an integral part of what we do. Restructuring the way we teach science, technology and mathematics would mean evaluation of the manner, methods and techniques we employ in teaching (input) these subjects in our schools, in relation to the desired outcome (general objectives) as envisaged in the National Policy on Education NPE (1979 revised 2005). This is to be done by:

$\checkmark$ Identifying the existing process

$\checkmark$ Identifying the existing outcome

$\checkmark$ Identifying the desired outcome

\section{The need to Restructure Science, Technology and Mathematics}

Nigeria is considered a developing nation because it is backward in the fields of science, engineering, technology and mathematics. To date, she cannot engage effectively in the following activities:-

- Production of capital goods such as tractors, lathe machines, drilling machines, cars, trains, and other earth moving equipments.

- Exploitation of her natural resources except with the help of foreigners who will normally provide the technology and expertise to undertake the exploitation of these natural resources.

- Mechanization of her agriculture i.e. crude implements are still used for agricultural production activities by a large percentage of those who are involved in agricultural production.

- Dependence on other countries for the supply of its spare parts for industrial machinery.

- Exportation of raw materials to other countries as against finished products.

- Inability to produce her own military hardware with which to defend herself, if the need arises.

A critical examination of our national level of development reveals that all the points itemized above are true about Nigeria as a nation. Thus, Nigeria is a technologically backward country. It is a consumer nation 
that depends on those that are able to develop because they have given the necessary attention to science and technology. The reasons for this situation include among others our inability to faithfully implement the NPE, lack of commitment, political will, and lack of trained teachers, inadequate funding and synergy between researchers, government and industries

\section{Challenges}

The Federal Ministry of Science and Technology, while trying to change the situation organized a summit in 2010 with a view to deal with this national problem. The summit observed the recent history of developed countries around the world, has confirmed that science technology and mathematics constitute the organic link that connects all the various sectors of the national economies such as agriculture, health, education, commerce and industry, etc. Undoubtedly, science and technology are the platforms that drive the potentials within these sectors through research and development programs, modern product techniques and process, development of pilot plants, commercialization of research results, amongst others. It therefore concluded that the active integration of a national culture, indigenous technology and, indigenous knowledge into science, engineering, technology (SETI) could facilitate an era of economic growth and skill development. This could also greatly facilitate life skills development, self employment and technological advancement.

It is painful that, in spite of our potentials in STM and the availability of over 80 Research and Development Institutes and centers, 100 functional Universities with Faculties of science, engineering and technology and over 100 polytechnics, Nigeria has not attained any appreciable capacity to translate the outcomes of her Research and Development (R\&D) into desirable outcomes. The country has over the last few decades, continued to witness a sharp decline in economic growth resulting in large scale unemployment, poverty and a collapsing manufacturing sector. The industrial manufacturing sector now contributes only a mere $3 \%$ to the GDP. Most of the technologies which Nigeria requires to sustain its modern domestic economic activities are imported from the industrialized nations and other developing countries such as China. The total reliance on imported foreign developed technologies, foreign consultants and contractors for executing Nigeria's infrastructural project such as roads, power, water supply, transportation, etc, besides being extremely costly, is also responsible for its inability to maintain them. Hence, we must restructure the way we teach science, technology and mathematics.

The critical challenges facing Nigeria's STM system include non commercialization of successful research results, non-demand driven STM activities, low value addition to industrial goods and services, lack of linkages between the Research Institutes and Private Sector. Duplication of functions among Research Institutions, lack of sustainable mechanism for funding R\&D activities, competition from foreign imports, low technological transfer mechanism, etc.

To reverse this unwholesome trend we must integrate the nation's specific, engineering and other professional endeavors into national economic development plans or projects (as S\&T is key to all other sectors). The Federal Ministry of Science and Technology (FMST) has to collaborate and encourage all stakeholders to partake in the process of restructuring, funding and popularizing all aspects of teaching science, technology and mathematics. This is the only way STM can facilitate the production of primary goods, enhance industrial processing and in manufacturing to enable the domestic economy compete favorably on the global stage. Indeed, for STM to play its role as a catalyst in the aspiration of the present Administration to make Nigeria one of the leading top 20 economies in the world by the year 2020, there is a compelling need to restructure our educational system to ensure effective integration of STM into the production of goods and services that have direct link with culture, economy and needs.

The educational system in general and the tertiary level in particular must be restructured to meet the following ends:-

(i) Identify and promoting strategies and procedures that would accelerate the commercialization of R\&D results in Nigeria;

(ii) Increasing public and private investments in $\mathrm{R} \& \mathrm{D}$ and innovation system;

(iii) Integrating STI activities with primary goods production, primary raw materials, industrial processing and manufacturing of capital/consumer goods and,

(iv) Reduction of the dependence of the industries and devise ways and means of promoting our own cultural/traditional industries. We must restructure and empower the tertiary level of education, especially the Polytechnics, so as to facilitate research and development of products through the popularization of indigenous efforts in research and development.

\section{Examples from other lands in respect of Science Technology and Mathematics and Skills Development}

Popoola (2009) reported that development in East Asia remains one of the global economy's most significant economic developments. Taking over from Japan, from the 1990's and beyond, China and the 'little tigers' of Singapore, Taiwan, and most recently the southeast Asian economies including Indonesia and 
Malaysia now occupy the top ranks of the world's economies in terms of not only their overall growth rates, but also of their human capital development, industrial and export growth rates. This was made possible because they had restructured their educational system and developed their indigenous technology and culture from within.

Literature on Chinese success story shows that, the rudiments of an industrial base were built on culture and traditional practices that are still being explored even now that, the country had opened up to capitalist influences. Some observers are of the view that China's current economic success story would not have been possible but for this meaningful synergy between traditional values and modernity. Today, regardless of her population, size and diversity, appreciable percentage of Chinese population is still largely agrarian living on basic Chinese culture and even pursuing aggressive export of part thereof. From drugs to wears, food stuffs and other consumables from china.

Chinese sense of moderation is indeed exemplary. Proud as they are of their culture, style taste and values, they have been making substantial gains from their creativity, exploring their environment and producing and packaging just anything, from bamboo through plants, herbs, fish and fish products to mention a few. We can talk of at least a partial convergence of tastes and preferences (between foreign and conventional) in china for example.

Popoola (2008) Singapore is yet another good story. Small as it is, Singapore has a diverse population of 2.5 million people comprising; 70 percent Chinese, 20 percent Malay, and 10 percent Indian and virtually no resources but responds meaningfully to the dynamics of globalization, information and telecommunication technology. With political economy deeply rooted in Singaporean tradition, the determination and willingness of her nationals reflects greatly in her annual earnings as distinct from what is prevalent in countries like Nigeria, and many other countries that are reservoirs of global energy resources. This is because it has heavily invested in science, technology and mathematics and has successfully planned to work along a knowledge based economy.

Making success of diversity, Malaysia was reported to have among its population ten times more ethnic Indians than Singapore does; it has thrice the number of ethnic Chinese than Singapore has. It has comparable links with Indonesia because communication between the two countries is relatively easy in the Malay language. Malaysia has recorded balanced success despite being a multi-racial society like Nigeria. This implies if structured meaningfully our diverse social formation could be a source and base for social, political and economic transformation, as is the case with Malaysia. It has garnered substantial goodwill from her culture potential so much so that, her hospitality industry is one of its strong revenue earners because its link with Malay traditional values.

\section{The link between Education and Science and Technology growth}

Adewoye (2008) education is vital for a country's development and economic growth. However, there are various reasons for the difference in the impact of education. One reason is that the quality of education has fallen so that years of scholarship do not produce the corresponding human capital. Another reason is that the marginal returns to education fell rapidly. As supply expanded, demand for educated labor remained stagnant. Moreover, this is due to the fact that factories are closing, employment of the skilled manpower become scarce and at the same time, this skilled manpower is under-performing.

Education is the foundation for the sustainable economic growth and broad social development. Still, we lack the skilled labour force and educated population we need to do this. A country needs teachers, doctors, accountants, journalists and managers to produce water and health facilities, good governance and private businesses. The link between education and economic development can be found in two main areas namely, provision of a skilled workforce and a more competitive economy, and an educated population that can develop informed views on good governance, the role of formal institutions and their country's role in an increasingly global world. Hence, education contributes to development through direct and indirect means. Economic development and growth go hand in hand with human capacity utilization and technological growth. Never has there been any country that made headway in economic growth relying on the availability of natural resources alone, without full utilization of the available human resources. Despite the abundance of raw materials in the form of agricultural produce and mineral (solid/liquid/gas) resources, the African continent remains the poorest and least developed because emphasis has mainly been on labor intensive production technologies.

The above situation gives a very bad picture of the level of our backwardness as a nation. To me, these circumstances came into being because our educational system is failing to meet the desired needs and aspirations due to the lack of qualified teachers, lack of political will and lack of synergy between government, Research Institutes and the private sector. To change the situation, the following measures must be restructured:- 


\section{(a) Teacher training, retraining and retention in reference to Science Technology and Mathematics Development}

The challenges the educational system is experiencing are in the forms of continuous failing standard of education, lowering morale of teachers, teacher trainees and the attitudes of the public towards teaching and the teaching profession, among others. The system we are operating is in a state of confusion because there are no teachers (qualified) to operate the system. Those in the field are not willing; those in training are there not because of interest but availability of the training (Akinbote 2007). It was found that students enroll in Colleges of Education to train as teachers not because they are interested in teaching but because it was the training available. In s study involving 1,200 students in 7 Colleges of Education, it was found that 525 (43.75\%) found their ways into Colleges of Education because there were no other institutions that could offer them admission, $150(12.50 \%)$ come in as a result of their personal desire to become teachers. The rest claimed that they were training as teachers to satisfy to the wish of their parents 45 (3.75\%); encouragement from friends 108 (9.00\%) and to use the training as a stepping stone $372(31.00 \%)$

The above study gives a very relevant picture of the perception of the younger ones towards teaching. Teachers being the foundation on which educational systems are built are lacking in attitude, aptitude and therefore willingness to deliver, one should not expect such potential teacher to be effective.

As at today, the Nigeria's educational system is not performing because there are so many concerns. All stakeholders are worried that the system is not producing the desired results due to the following realities, in many cases;

- Products of Basic Education not being able to read, write or speak good English

- Teachers not qualified (above 50\%)

- Teachers un-willing and frustrated

- Brain drain and continuous attrition to other services

- Presence of frustrated, un-employment graduates

- Armed Robbery and related crimes

- Examination malpractice(s) at all levels.

- Area Boys, yan-daba, Boko Haram and other groups

- Corruption penetrating all spares public life

- Frustrated Inspectors and Supervisory Headmasters

- Many others too numerous to mention

We have to embark of aggressive teacher training, re-training and retention measures that would attract the young ones who genuinely want to teach and train them towards developing the desirable attitude towards life in general and science in particular.

Accordingly, Joshi (2008) reflects that a person with a scientific attitude is expected to display the following characteristics: (a) open mindedness; (b) objectivity (c) freedom from superstitions; (d) belief in cause-effect relationship; (e) accuracy and truthfulness in reporting observations; (f) restriction to a method or procedure of solving a problem; (g) being up-to-date or current; (h) respect for other people's opinion, though may not be agreeable; (i) ability to distinguish between scientific evidence and scientific proof; and (j) ability to discern between fact and fiction.

These trained science teachers should be supported with appropriate conducive teaching- learning environment, laboratories, special rooms, books and a befitting welfare package that would put them at par with any other professional in the country.

\section{(b) Political will and Support for Educational System}

It is important to realize that no matter how good a policy is, political will is necessary to make it work. Nigeria as a nation is yet to free itself from the evils of Inferiority complex associated with colonialism, neo colonialism and economic dependence on the capitalist economy. Consequently, the technical inferiority of the traditional culture' vis-à-vis 'the technical superiority of the Europeans' largely accounts for our inability to patronize our own goods.. This imperialist ideology accounts for the neglect of, and destructive prejudice against, everything traditional.

To develop and work towards achieving our national vision for 2020, we must not only restructure our educational system, train teachers and provide conducive teaching learning environment, but we must learn to build and develop skills that are in harmony with our culture and way of life. Political will to drive the motive towards national goals will imply the need to differentiate between a rational and political consideration. Hence, the political class should support, encourage and patronize education to enable it produce the desired results. We must learn from China and other developing countries already discussed. 


\section{(c)Synergy between Tertiary Institutions, Government and Private Sector}

To effectively restructure science, engineering, technology and mathematics and therefore to serve our purpose, there must be a synergy between the above three groups, such linkages will ensure that the researches and innovations are taken further to commercialization, mass production and utilization. This would necessitate the application of the known economic benefits of science and technology to the advantage sustainable economic development and therefore as launch pads for industrialization.

We must therefore caution that, without political orientation and sense of direction on the part of the political class, restructuring of the educational system in general, science, engineering, technology and mathematics, in particular, will remain and continue to be an idea, waiting for people with the right attitude, courage and corresponding political will, to implement.

\section{Restructuring Measures to facilitate Skill Development, Employment and Productivity in Science, Technology and Innovation}

The National policy on Education is sound in the sense that it contains far reaching provisions that are still very relevant and in tune with arrangements necessary for the attainment of the mission and vision of the country. However, the problem is that of implementation as earlier discussed. After qualified teacher supply, political will and collaboration between the tertiary level of education, government and private sector, the schools should be provided with facilities in the right quantity, quality and be supported with all the recourses they need. Specifically, the following issues are briefly discussed;

\section{Provision of Infrastructural Facilities in our Schools}

The ideals of the society are supposed to be passed to the next generation by the school system. Presently, the older universities in Nigeria have obsolete tools and the newer ones cannot afford to equip their laboratories and workshops in our schools at present, it is regrettable to observe that polytechnics are not being supported as their products are rated as inferior to those with degrees. Students are not exposed to basic practical training because there are no suitable workshops. The government must invest monumental resources towards upgrading our educational infrastructures, especially in the polytechnics.

\section{Adequate financing of Research Institutions}

A good number of research institutions in Nigeria are not adequately funded. This continues to militate against effective research undertaking. India for example invested over three billion dollars in 1985 in some 1,300 research institutes working on electronics aeronautics and space, atomic energy, etc. In 1985, India spent $1.5 \%$ of her GNP on research and development compared with about $2.5 \%$ spent by the US. Nigeria's highest allocation figure was $0.43 \%$ in 1983 , which went down to $0.05 \%$ in 1992 and $0.23 \%$ in 2003 (popoola; 2009). This is very sad for a sector whose responsibility is to research into areas that will enhance development in the country.

\section{Polytechnics and Universities}

They require laboratories, workshops, and other facilities be developed for component analysis and for building prototypes of items to be produced. The idea is to knock down products of interest in the workshops, study and analyze each component in the laboratories to ascertain chemical composition, physical properties and other production parameters of interest and replicate such items. Government should encourage "Igbo made" items and should assist in improving the quality of these products so as to compete favorably with the imported ones.

\section{Industrial Espionage}

Highly technical and military technology is closely guarded by their proprietors. The secrets can be obtained either by direct investments or through espionage. Spies are often employed to collect top secrets and company documents required for developing such products, which they pass on to their sponsors for a fee.

\section{Need for Improvement in Energy Production, and Supply Distribution}

Energy is a necessary foundation for any industrial revolution. Nigeria has been flaring natural gas from oil wells for over 50 years. It has an abundant deposit of coal, yet the National Electric Power Authority (NEPA), now Power Holding Company of Nigeria (PHCN) cannot supply electricity to Nigeria. Industrial transformation can only thrive on a steady and sustainable supply of electricity. Since experience has shown that anything under government control never functions properly in Nigeria, it is imperative that for Nigeria to achieve technological breakthrough, PHCN has to be privatized. The ability of the privatized Power Holding Company of Nigeria (PHCN) to achieve the said aim is a topic for future discussion. The same should apply to other key sectors of the economy. 


\section{Conclusion}

From the foregoing, it is obvious that our educational system is not producing the desired results. This is due to the fact that the system is elitist, theoretical and lacks the necessary teachers, equipment and materials necessary for the training and production of students with the desired skills that are functional and therefore useful in the production of goods and services. There is therefore the need to restructure the educational system especially the polytechnics, monotechnics and the universities to enable the country transform towards science and technology, and, to make the vision 2020 a reality. To achieve this, there is the need to train teachers, political and synergy between Research Institutes, government and the private sector.

\section{References}

[1] Akinbote O. (2007) The Nigerian Primary School Teacher: Angel for instruction or Devil or Destruction? The Nigerian Journal of Educational Philosophy Vol. Vii (1) 35-40

[2] Federal Republic of Nigeria (2005) National Policy on Education, Lagos Federal Ministry of Information

[3] FMST (2010) Science and Technology summit held on $9^{\text {th }}$ July, 2010 Federal Ministry of Science and Technology, 2010 program Abuja

[4] Hornby, A.S. (2000) Oxford Advanced Learners' Dictionary of current English. Six Edition, Oxford University Press, London.

[5] Joshi, S.R. (2008) Teaching Science, New Delhi: APH Publishing Corporation

[6] Ogbu, Osita (2004) how can Science and Technology Policy aid Nigeria's reconstruction? African Technology Policy Studies http://www.atpsnet.org

[7] Okam C.C. (2009) Methods of Teaching the Sciences. A paper presented at the Academic staff orientation program. Umaru Musa Yar'adua University, Katsina. Unpublished.

[8] Popoola L. and Adewoye, A. (2009) Challenges of Science and Technology and Innovation Sustainable Development. Vol. II The Postgraduate School, University of Ibadan

[9] Popoola, L. (2008) Contemporary Issues in Sustainable Development. Lessons for, and Challenges to Nigeria. Vol. I The Postgraduate School, University of Ibadan

[10] Uwarfo V.O. (2009) Technology and Development in Nigeria: The missing link, J Hum Ecol, 28 (2): $107-111$ (2009) 